\title{
Learning Korean language in China: Motivations and strategies of non-Koreans
}

Dr. F. GAO ${ }^{1}$

Faculty of Education, University of Hong Kong

Postal address:

Room420, 4/F, Hui Oi Chow Science Building

Faculty of Education, HKU

Pokfulam Road, Hong Kong

Email: gaofang@graduate.hku.hk

\footnotetext{
1 Email: gaofang@graduate.hku.hk
} 


\section{Learning Korean language in China: Motivations and strategies of non-Koreans}

The ethnographic research reported in this article documents how a group of non-Korean families, whose children are participating in a Korean bilingual school in Northeast China, construct their motivations and strategies of learning Korean language. The main motivation of expectancy of further education opportunities and success in future career and strategies mainly in establishing Korean sociocultural context for Korean language acquisition are described. The positive attitude of non-Korean families toward Korean language studies highlights the functional importance of Korean language as a means of acquiring a larger benefit from China's economic marketization, especially increasing business contacts with South Korea. With the challenges of Korean language studies, this article argues that the increasing significance of trilingualism or even multilingualism in China's reform period implies the necessity of relevant policy initiations for the increasing needs of language acquisition.

Keywords: non-Korean; Korean language; integrative motivation; instrumental motivation; sociocultural context; multilingualism

(Number: 6084) 


\section{Introduction: Korean language and Korean language studies in China}

Second language acquisition has long been a common activity for a majority of the human species and is becoming even more vital as second languages themselves increase in importance (Cummins 1988; Thomas and Collier 1997). In China, second language acquisition is long-term concerned with teaching English as a second language or teaching Chinese as a second language especially for China’s 55 ethnic minorities ${ }^{1}$ (Feng 2007). However, alongside the rising saliency of ethnicity with the growing access to resources of social and cultural capital, teaching ethnic languages such as Korean as a second language for China's non-Korean people has an increasingly economic and socio-political importance. All of China's minority nationalities have their own languages, with the exception of the Hui and Manchu who use the Chinese language (Johnson and Chhetri 2000). There are 128 distinct languages spoken among China's minorities (Sun, Hu and Huang 2007). Some minority groups are bilingual, trilingual, or speak a variety of different languages, some of which are totally unlike each other. When the People's Republic of China (PRC) was established in 1949, there were only 11 minorities (Mongols, Zhuang, Uygurs, Koreans, Kazak, Xibe, Tai, Uzbeks, Kirgiz, Tatar, and Russians) who had their own written languages (Kwong and Xiao 1989). Currently, there have been 30 minorities with written forms since the government in 1958 began to create new scripts for minorities. Zhou (2000) categorizes 128 distinct languages spoken among China's minorities into three types: (1) minority languages with functional writing systems broadly used before 1949 have had regular bilingual education since 1949 
including Mongolian, Korean, Tibetan, Uygur and Kazak; (2) those minority languages with functional writing systems narrowly used before 1949 have had occasional bilingual education since 1949 such as Dai, Jingpo, Lisu, and Lahu so on; and (3) those without functional writing systems before 1949 have had limited or no bilingual education since then such as Dong, Yao, Tujia, Tatar and She so on. Korean, Mongolian, Tibetan, Uygur, Kazak and Kirgiz together are equally categorized as widely used and regulated as minority languages at the min kao min track in college entrance examination (Clothey 2005).

In comparison with other languages, Korean language is more or less unique in its functional significance, especially in China's reform period since the end of 1970s. There is a long history of Korean language teaching in China. Originally, Korean language course was called 'yanwen' in 1946. Then it was called 'chaoxian yu' in 1951, 'chaoxianzu yuwen' in 1959, 'chaoxian yuwen' in 1963, 'yuwen' in 1969, and 'chaoxian yuwen' in 1972. In the Korean concentrated regions, Korean bilingual schools (Korean and Chinese) are established from primary to higher education level (Ma 2004). The increasing economic contacts with Koreans, especially South Koreans in the Peninsula have led to the increasing significance of Korean language studies in China. The economic contacts with North Koreans involve border trade between China and North Korea around the Korean regions in China (Choi 2001; Kim 2003; Ma 2004). China and South Korea established formal diplomatic relations in 1992. Since then, the affordable labor, huge market and business opportunities in China began to attract South Korean 
direct investment. A growing number of South Koreans have migrated to China for business purposes (Kim 2003). South Korea's demonstrated international status and South Korean direct investment help the Korean language to acquire much importance (Choi 2001). Learning Korean is increasingly becoming popular among non-Korean people in China. Many non-Koreans attempt to play the roles of translators, tourist guides, information providers, and even business partners for South Korean people. Especially, Han majority people with a high proficiency in the Chinese language and sufficient understanding of Chinese government and laws are more welcomed by South Korean business people. Under the framework of motivations and strategies of second language learning, this article is intended to examine how a group of non-Korean families, whose children are participating in a Korean bilingual school, construct their motivations and strategies of learning Korean language. The research results point out that the increasing significance of trilingualism or even multilingualism in China's reform period implies the necessity of relevant policy initiations for the increasing needs of language acquisition.

\section{Motivations and strategies of second language learning}

One major concern to second or foreign language (L2) researchers has been the role played by attitudinal/motivational factors in L2 learning and acquisition. Motivation is often defined as a psychological trait which leads people to achieve a goal. In linguistics, sociolinguistics and second language acquisition, a number of language learning motivation models have been postulated. Through using the Attitude/Motivation Test 
Battery and various measures of second language achievement, Gardner's (2003) investigation into the relationship of second language attitude and achievement indicates that the correlations between achievement and motivation are uniformly higher than those between achievement and integrativeness, attitudes toward the learning situation, integrative orientation, or instrumental orientation. In Gardner's (1982, 2001) socio-educational model, motivation to learn the second language includes three elements. First, the motivated individual expends effort to learn the language. Second, the motivated individual wants to achieve a goal. Third, the motivated individual will enjoy the task of learning the language. For some language learners, mastery of a language may be a goal. For other learners, communicative competence or even basic communication skills could be a goal (MacIntyre, Clément, Dörnyei and Noels 1998). Gardner (1985) and others (Cookes and Schmidt 1991; Hudson 2000) identify two distinct orientations for learning a language: integrative and instrumental. According to Gardner (1985), integrative motivation is referred to as the learner's positive attitude toward the target language group and the desire to integrate into the target language community. Instrumental motivation, for Hudson (2000), is characterized as the desire to obtain something practical or concrete such as some social or economic reward from the study of a second language. Nevertheless, it is not intended to emphasize the integrative-instrumental dichotomy in terms of motivation referring to second language acquisition. Both integrative and instrumental motivation may lead to success. Rather, lack of either may lead to failure. For example, while examining the reasons for 
underachievement among some minority groups such as African Americans in the US, Ogbu (1998) points out that the minorities are less likely to succeed educationally because they do not value education and do not believe the possibility of social mobility. In addition, the way of explaining low participation and academic achievement in bilingual education among some minority groups in China frequently points to the negative attitude and motivation of the minorities toward educational success, economic benefits and integration into the mainstream (Hansen 1999; Pepper 1990).

Learning strategies are defined by O'Malley and Chamot (1990: 1) as 'special thoughts or behaviors that individuals use to comprehend, learn, or retain new information'. Oxford (1990: 1) defines them as 'actions, behaviors, steps, or techniques students use, often unconsciously, to improve their progress in apprehending, internalizing, and using the L2'. A significant number of scholars highlight the importance of individual learners, their motivation, and sociocultural context (Brown 2000, 2001; Cummins 1988; O’Malley and Chamot 1990; Oxford 1990; Thomas and Collier 1997). The rise of sociolinguistic and contextual approaches in second language research over the past decade reflects a growing recognition that learning language is a more complex process than merely acquiring linguistic structures, and that language learning and use are shaped by sociocultural process (Hall 1995; Losey 1995; McKay and Wong 1996; Zuengler 1989). According to the Prism Model produced by Thomas and Collier (1997), central to that student's acquisition of language are all of the surrounding sociocultural processes such as racial or ethnical sensibility occurring through everyday 
life. A socioculturally supportive environment may influence the process of second language studies positively. The sociocultural contextual factor in second language acquisition is concerned with the concept of family capital. Framed within Coleman's (1966) theory of family capital, different home variables such as family economic, cultural and social capitals affect children's second-language acquisition. There is a close linkage between second language acquisition and family investment in second language learning, parental culture capital and levels of parental involvement in education, and family social capital and access to familial and community resources. It may be difficult for parents to change their income levels, however, accumulating the other two dimensions of social capital and cultural capital are possible. High educational aspirations and parental valuing of second language, a supportive second-language environment, communication with the school and teachers, participation in school affairs, and involvement in social and cultural activities of the community can make a difference. According to Bourdieu (1990), cultural capital which consists primarily of what is perceived to be legitimate knowledge and behavior, whereas social capital relates to resources gained via relationships and/or connections with significant others. The concept of cultural capital is developed by Bourdieu to highlight that disparities in the educational attainment of children from different social classes attribute not only to economic obstacles, but also to the cultural habits and dispositions inherited from the family (Bourdieu and Passeron 1979). Checking second language homework, taking an interest in schoolwork, spending more time with their children at home and at cultural events in second language communication, may 
contribute to better achievement scores. Social capital provides access to social relationships or networks that promote their children's educational obtainment. Parents who have extended social networks can accumulate social capital by using those networks to gather information about how to make better decisions about what supplementary books to buy, and about how to have more effective communication in second language.

\section{Research methodology}

Data was collected from an ethnographic study with a group of non-Korean families, at the time of this study, whose children were participating in a Korean bilingual school, the researcher called FLK School in Liaoning Province (one northeastern province). The difficulties most of Korean schools in Northeast China are facing at current times are the declining enrollment of Korean students. Ethnic Koreans are more and more involved in intra-China and international mobility in the search of job opportunities (Choi 2001; Kim 2003). In the non-Korean families involved, in contrast, parents generally had relatively stable financial status in the mainstream economy. The population growth rate of Koreans is the lowest among China's 56 nationalities (Ma 2003). The increased mobility of Korean population and the decreasing population growth rate of Koreans heavily influence the Korean school enrollment. As a special-admit school, FLK used to accept only Korean students in the pre-reform period. The school had been overwhelmingly Korean since its creation in 1945. Rather, the growing number of non-Korean students referred to as 'Han' students at FLK marked a change to this pattern. The dramatic 
decline of Korean student intake yearly has led admission to FLK less ethnically selective in order to maintain enrollment. Such 'active attitude' on the supply side was associated with the positive response from the demand side toward Korean language studies. At the beginning of the autumn term 2006-07 when the fieldwork was undertaken, there were 327 students enrolled at FLK, which were composed of $83 \%$ Korean and 17\% non-Korean including Han, Manchu and Mango who were enrolled as 'Han'. In terms of performance tracks $(\mathrm{A}+, \mathrm{A}, \mathrm{B}+, \mathrm{B}, \mathrm{C}+$, and $\mathrm{C})$ at $\mathrm{FLK}$, the non-Korean students represented a heterogeneous student body. Out of the non-Korean students, a majority of them (40 out of 56) were top ranked. One fourth-grade class's top rank was composed of all 'Han' students, a fact which led all teachers and students to nickname the class the 'Han class'. The other fourth-grade class had a 'Han' student as the only one student at FLK as a whole, who skipped one grade with all A's achievement. A handful of non-Korean students were in the especially advantaged position at FLK. FLK valued the participation of non-Korean students who were relatively new comers to help to maintain enrolment. Their arrival seemed to increase the reputation of FLK as a model Korean school that was able to attract majority students. The non-Korean students were perceived as the 'models of ethnic unity'. Their success served as evidence that FLK was good enough for ethnic integration. This led to the special attention given to the students, which helped to promote their Korean language studies.

During the period of five-month fieldwork (September 2006 to January 2007), the nine non-Korean students in the two fourth-grade classes with their families participated 
in this research. Semi-structured interviews with the students and their parents were used to obtain deep insights into their motivations and strategies of Korean language studies. Family interview took place in their homes. The length of visit to each family ranged from one to two hours. Fathers, mothers, grandparents and children participated in interviews. Each interview was audio-taped and all tapes were transcribed. The racial breakdown of nine non-Korean informants was six Han, two Manchus and one Mongo. However, Chinese (Mandarin) was the exclusive language used in the nine non-Korean families. Each interview was conducted in Chinese, and translation into English involved the interpretative translation through making sense of the meanings that the interviewees conveyed. Interviews with the informants were supplemented by informal, natural conversations with students, or parents concerned.

\section{Research findings}

With an analysis of the ways that the non-Korean families constructed their motivations and strategies of learning Korean language, the collected data indicated their positive attitude toward Korean language studies for further educational opportunities and career choices and strategies in establishing a sociocultural home environment for second language acquisition.

\section{Non-Korean families' motivations of learning Korean language}


The non-Korean families in this study assumed that many Koreans inside and outside the locality were successful in educational, economic, and cultural realms, especially the cultural accomplishments which were reflected in the maintenance of ethnic language and culture. Especially those Manchu and Mongo parents widely understood that they have been much assimilated into the mainstream in comparison with Koreans who preserved their language and culture well. The South Korean direct investment in China and this labor export to South Korea entailed higher income for ethnic Koreans in China: 'I think Koreans are much rich', one parent remarked. 'They are making money as quickly as they can so that they don't need to work for the rest of their lives.' The remarks were echoed by another parent, who was running a small business in the community:

They, I mean, the self-employed Korean merchants, have done very well. They have their own extended business networks that provide start-up money for businesses. For those who worked in restaurants, in factories in South Korea, they come back home with a certain level of wealth that means a lot: flats, cars and so on.

The locality where FLK was located, with its relatively late industrial development at the turn of the century has been spatially dominated by closely packed basic terraced housing. Sooner after the Housing Act and its influential 'Renewal Strategies', the new and expensive high-rise flats appeared. Most of the flats were visually dominated by the 
Korean residents. One estate named ‘Gaoli Garden’ was especially targeted at Korean residents.

The economic benefits from increasing business contacts with South Koreans largely promoted Korean language studies among the non-Koreans. According to the parents, they believed that their children with the competence in Korean, Chinese and English through attending Korean school would be in an advantageous position while competing with both Koreans and others in college admission and future career. The parents believed that cultivating Korean language was strategically valuable in order to give their children the necessary tools (especially language) with which to enhance and to full exploit it. As one parent expressed:

I know they [Korean Chinese] are proud of being Korean because of all the success they feel. I also believe that learning Korean will benefit us. This will give our children an advantage, an edge in a world that is rapidly getting smaller.

Educational aspirations that motivate children and youth to strive for educational success are shaped by the expectations of significant others, notably, parents, teachers, and peers (Campbell 1983; Davies and Kandel 1981; Hauser, Tsai and Sewell 1983). The non-Korean parents generally had high expectations of their children's school education, which strongly influenced the learning motivations of their children. In terms of the motivations of the non-Korean students in learning Korean language, there was a direct 
link between their Korean language studies and their pursuit of further education and future career. According to one student informant:

My parents want me to have a better and easier life. I want that kind of education which really leads a good career such as being an interpreter in future. My parents have enforced in me that I should speak more Korean and that's the thing I should do right now.

The proficiency of Korean and Chinese was considered important for the career choices among the student informants. One student told me:

I would like to learn Korean better. There are more people in China speaking Korean. Many South Koreans move their companies/factories to China. They need people to be proficient in Korean, Chinese and even English. I am only able to learn Chinese and English in Han schools. But here I can learn Korean too. This is an advantage for my future career.

For the students, expectations for schooling were primarily to 'attend a good school, get all A's, get into college, find a steady job and earn a decent living.' In their minds, they needed to learn one more language as a result that they were probably more excellent than others. This was generally compared with Korean students at FLK. It was 
the fact that the non-Korean students expressed their acceptance of educational success among ethnic Koreans. They described Korean students as hardworking students, some of whom excelled in academic work, while some others excelled in sports (e.g. slipping rope). Rather, the non-Korean students held superior self-image and generally claimed that they were studying better than Korean students. One student informant said this:

I attend Korean school, and thus know more knowledge than other Han students. I am in an advantageous position when I compete with both Korean and Han counterparts. As long as I have this kind of education, I am fine...think success would be having a job to earn more money, and obtaining financial safety.

The valuing of Korean language was coupled with the need to capitalize on the Chineseness to accommodate the demands of the mainstream society. The non-Korean families held a negative attitude toward sub-standard quality of Korean bilingual schools, especially in Chinese language studies. The Chinese language textbooks at FLK had been two grades lower than the textbooks used in Han schools. The new curriculum design in Korean bilingual schools promulgated in 2002 gave the equal attention to Korean, English, and Chinese, three of which accounted for 38.4\% of the curriculum load (Jiang 2006). The teaching of trilingualism led FLK to provide lesser hours of Chinese language courses per week. The bilingual teaching in the non-language subjects was considered helpful for Chinese language acquisition. Rather, FLK was a typical Korean school, 
where Korean was the main medium of instruction, whereas Chinese was only taught as a subject. Many students emphasized that they had to pay more attention to Chinese language studies. One student informant commented:

My parents and I consider Chinese language to be the most important one. I need to pay more attention to Chinese language because I will go to Han school for junior-secondary education. Yes, there is no Korean language in Han schools. But I will complete all Korean basic alphabets in primary education so that I won't forget Korean language in future.

\section{Non-Korean families' strategies of learning Korean language}

The non-Korean families struggled to create a supportive second-language environment for the Korean language acquisition of their children. The families generally held a high educational aspiration and valued second language studies. The non-Korean parents lacked necessary qualification in Korean language. Rather, they were committed to these educational strategies for the creation of a supportive sociocultural context in second language acquisition. Most of the non-Korean students at FLK came from families, where either of their parents had no knowledge of Korean language and culture. One parent informant said this: 
It is true that we can't help our child in Korean language. Both of us are Han. We have no knowledge of Korean. So he [the child] has to ask his Korean classmates for help. Their parents are Korean and are able to help their children with Korean language studies.

However, the parents generally indicated that they spent more time with their children at cultural events in second language communication and created a Korean culture environment at home. One parent informant told me:

Yes, we cannot speak Korean. But it doesn't mean that we cannot do anything for our children. In order to familiarize them with Korean language and culture, we buy Korean books and cook Korean food like kimche at home. We would like to create a Korean environment at home to help them with Korean language studies.

While these non-Korean parents could not check second language homework and help their children with Korean language problems, they generally attempted to compensate this disadvantage, for example by learning Korean language or employing private tutor. One student informant remarked:

There is no Korean in my family. My parents are both Han. The fact that my parents don't know Korean influences my achievement. When I was in the kindergarten, my 
mama joined the Korean language remedial class with me in order to help me with Korean language problems.

FLK School was a 12-year Korean bilingual school (including three-year pre-school education and nine-year compulsory education). Most of the non-Korean students began their study at FLK from pre-school grades. Their parents were allowed to sit in the classroom in order for their children to adapt rapidly to the physical and psychological aspects of Korean school life and to become fluent in Korean. One non-Korean student informant told me:

I have to learn Korean well. I feel I am obligated to my family for the sacrifices they have done to me. When I was a pre-schooler, my parents accompanied with me to school everyday, and sat in the Korean remedial class all the time in order to help me with my Korean language studies.

Out of the nine non-Korean families, parents generally received tertiary education with relatively stable financial status in the mainstream economy. With the sufficient family income, the families provided more tutorial assistance for their children. Many parents paid tuition for their children to have private lessons in Korean language. One student informant remarked: 
In addition to the Korean language courses in our school, my parents send me to attend a outside-of-school Korean language remedial class. They also employ one private tutor to help me with my Korean language.

FLK School was the only Korean school in the locality. It acted as a cultural and psychological center for ethnic Koreans through a series of public-open activities such as the sports meetings mainly with those parents who helped with fundraising, and attended performances and competition such as running relays and tug of war. The non-Korean parents were universally active in these activities. Through participation in school affairs, and involvement in social and cultural activities of the community, the non-Korean parents got access to Korean families and succeeded in employing highly qualified ethnic Koreans as private tutors for their children's Korean language studies. One non-Korean parent said this:

I have Korean friends. We get in touch with each other during parents meeting at school or cultural activities in the community. They help me to search for qualified Korean teachers for my child’s Korean language studies.

The non-language subjects were provided through Korean at FLK. As a result, in additon to the Korean language subject, the non-Korean students also faced the difficulty in searching for help from their parents in such subject as mathematics given in Korean. One 
student informant commented:

My baba can speak a little Korean, but my mama doesn’t know Korean language at all.

If I have any problem with my homework, I have to keep it to ask the teacher for help the next day when I go to school. This puts me in a disadvantaged position while competing with others.

However, the non-Korean families attempted to solve this problem by translating the academic problems into Chinese. Even though the families expressed their concern about the shortage of Korean language proficiency, they generally had a higher educational background and parental involvement in both family and school education. One student informant said this:

When I have problems with maths, my parents ask me to translate into Chinese and then ask them. Then they are able to help me with those problems. They are always patient with me. It [translating into Chinese] is a means many of us here use to ask for help from parents. It always works.

\section{Discussion and conclusion: Multilingual education in China's reform period}

The profound forces of globalization with the accelerating flow of goods, people, data and information across national borders are lending growing weight to the 
multilingualism within the context of multiculturalism (Suárez-Orozco and Qin-Hilliard 2004). The non-Korean families in this research constructed both integrative and instrumental motivations for Korean language acquisition, referred to as positive attitude toward the Korean language group and pragmatic attitude toward educational success and economic advancement. With the importance of parental involvement in education, the non-Korean families concerned adopted strategies to promote their children's Korean language acquisition. These strategies mainly concentrated on the creation of a sociocultural context including cooking Korean food, buying Korean books, learning Korean language, providing private tuition, and translating school work in Korean into Chinese. While the promotion of trilingualism in the school curriculum has many positive aspects, an allocation of more periods to language subjects may cause imbalance in the design of curriculum. The over-allocation of language subjects in the curriculum creates a problem with schools about which subjects, if any, should be sacrificed in order to provide sufficient periods to language teaching. This result in many ethnic schools is always that the lower status subjects such as art and craft, music and physical education become a sacrifice, which is against from the development of students' all-round potential. The research findings with the increasing functional significance of trilingualism have strong implications for the curriculum design and relevant policy initiations for language acquisition.

In a pluralist country like China, education for its population is never separated from multiculturalism and diversity. Fei Xiaotong’s (1991) ‘duoyuan yiti geju’ which has been 
translated by (Postiglione 2007) into 'plurality within the organic unity of the Chinese nationality’ with its functionalistic value highlights the national unification and cultural pluralism of China. China's economic and political rationales for literacy have motivated legislation to define literacy as functional. Literacy is a vehicle for the maintenance and transmission of cultural values and beliefs (Zhou 2005). The presence of a national policy which recognizes the functional value of ethnic diversity and promotes a provision of ethnically-oriented educational experiences seems to be a necessary condition for the preservation of ethnic culture and identity (Feng 2007; Lee 1986; Olivier 1993). The very survival of a multicultural or a multilingual country not only implies the cultural pluralism among its ethnic minorities, but also implies the pluralism among its majority people. It is a two-sided acceptance: minority people learn majority language and culture, and majority people learn minority culture and language. China has been experiencing a huge social transformation during the reform period. The increasing mobilization of population puts different ethnic groups in various contact situations, which easily leads to conflict and cultural misunderstanding (Postiglione 2007). The solutions to the problems would be unavoidably limited without governmental policies of cultural/linguistic pluralism (Feng 2007). The development of school programs to serve the children and youth who may need language as a second or even third language needs to recognize the complexity of providing appropriate educational services within the normally rather rigid framework of an educational system. For children and youth in China, the fluency in mainstream language is important for their future education and career choice. The 
English language is vital for them to participate into the global world. The Korean language as the second/third language with its functional value is a key symbol of participation into business contacts with South Koreans. Whether students in China should be provided with education through Chinese or English and whether minority language teaching should be paid more attention in China's market economy pose more questions than answers to policy makers. However, there is a necessity to support a policy of educational development under the consideration of upward social mobility among ethnic minorities and their cultural and language preservation (Lee 1986; Olivier 1993). With the increasing importance of multilingualism and multiculturalism, it is clear that the language teaching in China is largely dependent upon an alteration of government priorities including multi-linguistic and multicultural themes in curriculum and teaching practices. 


\section{Note}

1. The Constitution adopted in 1982 defines the People's Republic of China (PRC) as a “unitary multi-national state” (tongyide duominzu guojia) composed of the people of all its 56 nationalities (minzu) with a total population of 1.30628 billion (NBSC 2005). The majority of China's population belongs to the Han Chinese (90.56\%), whereas the 55 officially recognized minority nationalities account for about $9.44 \%$ of the total population (NBSC 2005). There are also 1,072,642 people belonging to unspecified and unclassified minorities, $0.8 \%$ of the total population, according to the fifth national census in 2000 . 


\section{Notes on contributor}

GAO Fang is a Post-doctoral fellow in the Centre for Advancement of Chinese Language Education and

Research in the Faculty of Education, University of Hong Kong. She graduated from Ph.D. program in

Education at the University of Hong Kong. Her Ph.D. dissertation examines the schooling experiences of Korean students behind the model minority stereotype. 


\section{References}

Bourdieu, P. 1990. The logic of practice. Cambridge: Polity Press.

Bourdieu, P., and Passeron, J. C. 1979. The inheritors: French students and their relation to culture. Chicago: University of Chicago Press.

Brown, H. D. 2000. Principles of language learning and teaching (Fourth Edition). New York: Longman.

Brown, H. D. 2001. Teaching by principles: An interactive approach to language pedagogy (Second Edition). New York: Longman.

Campbell, R. T. 1983. Status attainment research: End of the beginning or beginning of the end? Sociology of Education 56: 47-62.

Choi, W. G. 2001. The Korean minority in China: The change of its identity. DEVELOPMENT AND SOCIETY 30: 119-141.

Clothey, R. 2005. China's policies for minority nationalities in higher education: Negotiating national values and ethnic identities. Comparative Education Review 49, no. 3: 389-428.

Coleman, J. S., et al. 1966. Equality of educational opportunity. Washington, DC: U.S. Government Printing Office.

Cookes, G., and Schmidt R. W. 1991. Motivation: Reopening the research agenda. Language Learning 41, no. 4: 469-512. 
Cummins, J. 1988. From multicultural to anti-racist education: An analysis of programs and policies in Ontario. In Minority education: From shame to struggle, ed. T. Skutnabb-Kangas and J. Cummins. Clevedon: Multilingual Matters.

Davies, M., and Kandel, D. B. 1981. Parental and peer influences on adolescents' educational plans: Some further evidence. American Journal of Sociology 87: 363-387.

Fei, X. T. 1991. Zhonghua minzu yanjiu xin tance [New Explorations in China's Ethnic Studies]. Beijing: Chinese Academy of Social Sciences Publishing House.

Feng, A. W. (Ed.). 2007. Intercultural space for bilingual education. In Bilingual education in China: Practices, policies and concepts, ed. A. W. Feng., 259-286. Clevedon: Multilingual Matters.

Gardner, R. C. 1982. Language attitudes and language learning. In Attitudes towards language bariation, ed. E. Boudhard Ryan and H. Giles., 132-147. Edward Arnold.

Gardner, R. C. 1985. Social psychology and second language learning: The role of attitudes and motivation. London: Edward Arnold.

Gardner, R. C. 2001. Language learning motivation: The student, the teacher, and the researcher. Texas Papers in Foreign Language Education 6: 1-18.

Gardner, R. C. 2003. Attitudes, motivation, and second language learning: A meta-analysis of studies conducted by Gardner and associates. Language Learning 53: 123-163. 
Hall, J. K. 1995. (Re)creating our worlds with worlds: a sociohistorical perspective on face-to-face interaction. Applied Linguistics 10, no. 1: 206-32.

Hansen, M. H. 1999. Lessons in being Chinese: Minority education and ethnic identity in southwest China. Seattle: University of Washington Press.

Hauser, R. M., Tsai, S. L., and Sewell, W. H. 1983. A model of stratification with response: Error in social and psychological variables. Sociology of Education 56: 20-46.

Hudson, G. 2000. Essential introductory linguistics. Blackwell Publishers.

Jiang, Y. D. 2006. Chaoxianzu zhongxiaoxue shuangyu jiaoyu yanjiu, [Investigation into Korean bilingual primary and secondary education]. Paper presented at the Korean Chinese Education Forum (1906-2006), August 17-19, in Yanbian University, China.

Johnson, B. and Chhetri, N. 2000. Exclusionary policies and practices in Chinese minority education: A case of Tibetan education. Current Issues in Comparative Education 2, no. 2: 1-13.

Kim, S. J. 2003. The economic status and role of ethnic Koreans in China. In The Korean diaspora in the world economy, ed. C. F. Bergsten and I. Choi. Washington, DC: Institute for International Economics.

Kwong, J. and Xiao, H. 1989. Educational equality among China's minorities. Comparative Education 25, no. 2: 229-43. 
Lee, C. J. 1986. China's Korean minority: The politics of ethnic education. Boulder: Westview Press.

Losey, K. M. 1995. Gender and ethnicity as factors in the development of verbal skills in bilingual Mexican American women. TESOL Quarterly 29, no. 4: 635-61.

Ma, C. H. 2004. Language practice and identity of Korean-Chinese bilinguals in Yanji. PhD diss., Michigan State University.

Ma, R. 2003. Zhongguo ge zuqun zhijian de jiegou xing chayi, [The structural disparities between China’s ethnic groups]. Shehui kexue zhanxian 4: 174-185.

MacIntyre, P.D., Clément, R., Dörnyei, Z., and Noels, K.A. 1998. Conceptualizing willingness to communicate in a L2: A situated model of confidence and affiliation. Modern Language Journal 82: 545-562.

McKay, S. L., and Wong, S. L. C. 1996. Multiple discourse, multiple identities: investment and agency in second-language learning among Chinese adolescent immigrant students. Harvard Educational Review 66: 577-608.

NBSC. 2005. China statistical yearbook. Beijing: China Statistical Press.

Ogbu, J. U. 1998. Voluntary and involuntary minorities: A cultural ecological theory of school performance with some implications for education. Anthropology and Education Quarterly 29, no. 2: 155-188.

Olivier, B. V. 1993. The implementation of China's nationality policy in the northeastern provinces. San Francisco: Mellen Research University Press. 
O`Malley, J., and A. Chamot. 1990. Learning Strategies in Second Language Acquisition. Cambridge: Cambridge University Press.

Oxford, R. 1990. Language learning strategies. New York: Newbury House Publishers.

Pepper, S. 1990. China's education reform in the 1980s: Policies, issues, and historical perspectives. California: Institute of East Asia Studies.

Postiglione, G. A. 2007. Ethnic minority policy in education: The educational challenge of harmonious multiculturalism. Paper presented at the Beijing Forum: The harmony of civilizations and prosperity for all diversity in the development of human civilization, in Beijing, China.

Suárez-Orozco, M. M., and Qin-Hilliard, D. B. (Eds.). 2004. Globalization: Culture and education in the new millennium. Berkeley: University of California Press.

Sun, H. K., Hu, Z. Y., and Huang, X. 2007. Zhongguo de yuyan [The languages of China]. Beijing: The Commercial Press.

Thomas, W. P., and Collier, V. 1997. School effectiveness for language minority students. Washington: National Clearinghouse for Bilingual Education.

Zhou, M. L. 2000. Language attitudes of two contrasting ethnic minority nationalities in China: The 'model' Koreans and the 'rebellious' Tibetans. International Journal of the Sociology of Language 146: 1-20.

Zhou, M. L. 2005. Legislating literacy for linguistic and ethnic minorities in contemporary China. Current Issues in Language Planning 6, no. 2: 102-121. 
Zuengler, J. 1989. Identity and IL development and use. Applied Linguistics 10, no. 1: 80-96. 